\title{
Effect of Thalidomide on Cox-2 expression in bleomycin-induced pulmonary fibrosis in mice
}

\author{
Mohammad Jafar Rezaie ${ }^{1}$, Ayoob Rostamzadeh ${ }^{2}$, Ghazal Keshavarz ${ }^{3}$, Mansour Amraei ${ }^{4,5}{ }^{\circledR}$, Ardeshir \\ Moayeri $^{6, *}$ (1)
}

\begin{abstract}
${ }^{1}$ Department of Anatomical Sciences, Faculty of Medicine, Kurdistan University of Medical Sciences, Sanandaj, Iran

${ }^{2}$ Department of Anatomy and Neuroscience, Faculty of Medicine, Shahrekord University of Medical Sciences, Shahrekord, Iran

${ }^{3}$ Department of Anatomical Sciences, Faculty of Medicine, Kermanshah University of Medical Sciences, Kermanshah, Iran

${ }^{4}$ Biotechnology and Medicinal Plants Research Center, Ilam University of Medical Sciences, Ilam, Iran
\end{abstract}

${ }^{5}$ Department of Physiology, Faculty of Medicine, Ilam University of Medical Sciences, Ilam, Iran

${ }^{6}$ Department of Anatomy, Faculty of Medicine, Ilam University of Medical Sciences, Ilam, Iran

Correspondence

Ardeshir Moayeri, Department of Anatomy, Faculty of Medicine, llam University of Medical Sciences, Ilam, Iran

Email: moayeri46@medilam.ac.ir

\section{History}

- Received: Nov 07, 2018

- Accepted: Jan 13, 2019

- Published: Jan 31, 2019

DOI :

https://doi.org/10.15419/bmrat.v6i1.518

\section{Check for updates}

\section{Copyright}

(C) Biomedpress. This is an openaccess article distributed under the terms of the Creative Commons Attribution 4.0 International license.

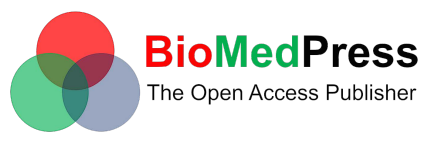

\begin{abstract}
Introduction: Lung fibrosis is a progressive, fatal disease that is characterized by increasing fibroblasts proliferation and extracellular matrix precipitation. Studies have shown that cyclooxygenase2 (Cox-2) could play a crucial role in the pathogenesis of lung fibrosis. In the current study, the effect of thalidomide on bleomycin-induced pulmonary fibrosis was qualitatively studied in a laboratory animal model.Methods: Thirty-two adult male C57BL/6 mice were randomly assigned to the following four groups: Group one received $2 \mathrm{mg}$ bleomycin, group two received bleomycin in addition to $4 \mathrm{mg}$ of thalidomide; group three received $4 \mathrm{mg}$ of thalidomide, and Group 4 received $0.1 \mathrm{mg}$ of $0.5 \%$ carboxymethyl cellulose (CMC) via intraperitoneal (IP) administration. Finally, the expression of Cox-2 protein and the percentage of contact points of alveolar spaces and pulmonary connective tissue were determined. Results: Our results showed that in the Bleo + Thal group compared to the Bleo group, the percentage of contact points of pulmonary connective tissue decreased significantly $(P<0.001)$, while the percentage of contact points among the alveolar spaces increased significantly $(P=0.01)$. Also, immunohistochemical studies have demonstrated the number of $\mathrm{Cox}_{-2}{ }^{+}$cells in the volume unit in the Bleo + Thal group decreased significantly in comparison with the group that received only Bleo $(P=0.012)$. Conclusion: In conclusion, these results suggest thalidomide could alleviate the bleomycin-induced lung fibrosis and decreases the expression of Cox-2 protein.
\end{abstract}

Key words: Bleomycin, Cyclooxygenase 2, Lung fibrosis, Mice, Thalidomide

\section{INTRODUCTION}

Lung fibrosis is the end stage of a diverse group of pulmonary disorders known as interstitial lung diseases. The most common disease among this group is idiopathic pulmonary fibrosis (IPF) ${ }^{1}$. IPF is a chronic progressive disease with unknown pathogenesis, which has the worst prognosis among the interstitial lung diseases with the mean survival time of 2-4 years after diagnosis, and the prevalence rate of 20 and 13 cases per 100,000 male and female respectively $^{2}$. It was previously assumed that the pathogenesis of IPF is related to chronic pulmonary inflammation $^{3}$. According to this theory, unknown stimulators lead to chronic inflammation, which causes fibrosis $^{3}$. Because interstitial inflammation could play a crucial role in pulmonary fibrosis, anti-inflammatory adrenocorticosteroids have been widely used for IPF patients. However, anti-inflammatory treatments were not so successful in treating IPF ${ }^{4}$. It seems that other factors may contribute to this process. Recent studies have shown that tissue remodeling after epithelial injury is another important process in IPF pathogenesis ${ }^{5}$. Moreover, pulmonary fibrosis may be induced by various factors, including herpes virus, silica, asbestos, butylated hydroxytoluene, radiation, and bleomycin. Bleomycin is indeed a chemotherapy agent which is used in cancer treatment, and one of its common adverse effects is pulmonary fibrosis. Today, this medication is used to induce fibrosis in animal models ${ }^{6,7}$. Furthermore, studies have shown that cyclooxygenase-2 (Cox-2) is an important marker involved in the pulmonary fibrosis process. Cox-2 is the catalyst in the biosynthesis of prostaglandins from arachidonic acid ${ }^{8}$. In addition, the Cox-2 pathway is clinically important in the pathogenesis of pulmonary fibrosis. Thus, factors influencing Cox-2 expression might affect the process of pulmonary fibrosis. In this regard, studies have demonstrated that the non-steroidal anti-inflammatory drugs (NSAIDs)which are commonly used in reducing inflammation, pain, and fever may alter the expression of $\mathrm{COX}_{2}$ protein. In 1991, two distinct types of Cox protein, namely Cox-1 and Cox-2, were reported, while Cox3 has recently been discovered ${ }^{9}$. Cox-1 is continuously expressed in many tissues, while Cox-2 is expressed when the tissue is stimulated by inflamma- 
tion or mitogen stimulators ${ }^{10}$. It has been demonstrated that inflammation and Cox protein could play crucial roles in the development of pulmonary fibrosis and could be considered as markers of the condition. Therefore, researchers have evaluated the use of antiinflammatory agents in inhibiting pulmonary fibrosis. Furthermore, previous studies have shown that thalidomide can attenuate inflammation ${ }^{11}$. Thalidomide, a derivative of glutamic acid, was first introduced for the treatment of nausea in pregnant women. Due to its teratogenic effects, the drug was withdrawn from the pharmaceutical market in 1960. A few years later, it was confirmed that the drug's adverse effect is secondary to its inhibitory effect on angiogenesis in developing fetal limb bud ${ }^{12}$. Fujita et al. reported the important function of thalidomide in the treatment of cancer patients through modulation of the Cox pathway $^{13}$. Moreover, several clinical studies have confirmed the efficiency of thalidomide and its analogs in various diseases including rheumatoid arthritis ${ }^{14,15}$, Castleman's disease ${ }^{16}$, and Crohn's disease ${ }^{17}$. Moreover, thalidomide has been used in the treatment of some malignancies including AIDS-associated Kaposi sarcoma ${ }^{18}$, renal cell carcinoma $^{19}$, and myelodysplastic syndrome ${ }^{20}$. It is worth to mention that different fibroproliferative diseases have common pathogenesis processes ${ }^{21}$. Based on the evidence provided by previous studies on thalidomide ${ }^{22-24}$, in the current study, the effect of thalidomide on the expression of Cox-2 protein in bleomycin-induced pulmonary fibrosis was investigated in C57BL/6 mice.

\section{METHODS}

\section{Animals and ethics}

Thirty-two male C57BL/6 mice with the average weight of 20-25 g and aged 6-8 weeks were studied. The mice were obtained from the Pasteur Institute (Tehran, Iran). This study was approved by the Ethics Committee of Kurdistan University of Medical Sciences (IR.MUK.REC.1395.382).

\section{Groups and treatments}

In this experimental study, adult male C57BL/6 mice (Purchased from Pasteur Institute of Iran; Tehran) weighing 20-25 g on average at the age of 6-8 weeks were randomly allocated to four groups, each including eight mice. Group one (Bleo): $2 \mathrm{mg}$ of bleomycin sulfate (Nippon Kayaku, Tokyo, Japan) were dissolved in $0.1 \mathrm{ml}$ carboxymethyl cellulose (CMC) (Sigma Corp. St. Louis, Missouri, USA) $0.5 \%$, and then administered via intraperitoneal injection on Days 1, 8, and 15. Group two (Bleo+Thal) received bleomycin as was mentioned for the Bleo group plus $4 \mathrm{mg}$ thalidomide (Sigma Corp. St. Louis, Missouri, USA) dissolved in $0.1 \mathrm{~mL} \mathrm{CMC} 0.5 \%$ via intraperitoneal injection five times a week for one month. Group three (Thal) received $4 \mathrm{mg}$ thalidomide (Sigma, USA) dissolved in $0.1 \mathrm{~mL}$ CMC $0.5 \%$ via intraperitoneal injection five times a week for one month, and Group four (CMC) received $0.1 \mathrm{~mL} \mathrm{CMC} 0.5 \%$ via intraperitoneal injection five times a week for one month. At the end of the experiment, the animals were sacrificed using an overdose of ketamine. The thorax was opened, the lungs were removed, and after being washed with PBS, the lungs were placed in formalin $10 \%$. Then, the tissues were dehydrated at different levels, molded, and sections with $6-\mu \mathrm{m}$ thickness were prepared. The samples were then stained using hematoxylin (Merck KGaA, Darmstadt, Germany) and eosin (Sigma-Aldrich Corp. St. Louis, Missouri, USA) (H \& E) to investigate the histological changes, and stained by Masson's trichrome (Sigma Corp. St. Louis, Missouri, USA) to evaluate the collagen deposition within the lung parenchyma under light microscopy (Carl Zeiss Microscopy GmbH, Jena, Germany). Morphological changes of the pulmonary tissue were evaluated. Moreover, the percentages of alveolar spaces and pulmonary connective tissue were determined by point-counting methods per volume unit. In this method, for each group, 15 fields of 15 sections were examined with $40 \mathrm{X}$ magnification.

\section{Immunohistochemical analysis}

The expression of Cox-2 protein was evaluated by immunohistochemistry. Sections with the thickness of $6 \mu \mathrm{m}$ were prepared by sectioning tissue blocks embedded in solid paraffin. The sections were mounted on silanized slides (Sigma, USA). The slides were then placed in an oven at $60{ }^{\circ} \mathrm{C}$ and deparaffinized and rehydrated in three steps. After that, antigen retrieval was performed by applying citrate buffer solution for 17 minutes. Endogenous peroxidase activity was blocked by adding $3 \% \mathrm{H}_{2} \mathrm{O}_{2}$ for $10 \mathrm{~min}$ utes. To neutralize extra proteins, $2 \%$ bovine serum albumin solution (Pars Tos, Iran) was used. The solution obtained was then incubated overnight with rabbit-specific primary antibody against Cox-2 (Abcam, Cambridge, UK) at $4^{\circ} \mathrm{C}$. Then, the samples were rinsed, and incubated with rabbit-specific secondary antibody against Cox-2 (Abcam, England) was added. After rinsing, diaminobenzidine (DAB) (Roche, Germany) was added, and the samples were kept in darkness for 10 minutes. The nucleus staining was performed by using hematoxylin, and the samples were 
mounted on slides. Cox- $2^{+}$cells were counted using Motic software (Motic Image Plus 2.0, Richmond, Canada). The software calibration was performed using a scaled slide to measure in micrometers, and the number of Cox-2 expressing cells was determined in 15 fields of 15 sections $^{25}$.

\section{Statistical analysis}

The experimental results are presented as mean \pm Standard Deviation (SD). Following the assurance of normal distribution of data, data significance and correlations was estimated using one-way analysis of variance (ANOVA) with the Newman-Keuls posthoc test in GraphPad Prism 5.0 (GraphPad Software, Inc., San Diego, CA), and also in all the tests, $\mathrm{P}<0.05$ was considered statistically significant.

\section{RESULTS}

\section{Histopathological and immunohistochemi- cal qualitative results}

The qualitative results obtained from the histopathological evaluation of the pulmonary tissue demonstrated that the level of inflammation and fibrosis, the deposition of collagen fibers, and the expression of Cox-2 protein were different across various experimental fibrotic changes were observed. In addition, the infiltration of inflammatory cells in alveolar spaces, disorganization of the alveolar structure, impairment of alveolar walls, development of cystic changes in alveoli, and the amount of connective tissue also increased (Figure 1A). Collagen deposition in the interstitial connective tissue was observed as blue fibers in the Masson's trichrome staining (Figure 1B). According to the results obtained from immunohistochemical studies, Cox-2-expressing cells were present between the epithelial cells of the alveoli and the connective tissue (Figure 1C).

Histological and Immunohistochemical analysis on the lung tissue in Thal group shows that the lung tissue alveoli have a normal appearance. There is no evidence of the congestion and inflammatory cells. Also, there is no evidence of interstitial tissue remodeling (Figure 2A). The results of photomicrographs from Masson's trichrome staining showed areas with lower level collagen (Figure 2B). Cox-2 immunohistochemistry (anti- Cox-2) shows that Cox-2+ cells are rarely observed (Figure 2C).

However, the Bleo+Thal group showed a relative reduction in the number of inflammatory cells, thinner alveolar walls, and a better organization of the alveolar structure. Fewer changes associated with alveolar impairment were observed. Moreover, remodeling in connective tissue is less visible than group one.
Also, both type 1 and type 2 pneumocyte cells can be seen (mostly type 2 ) in epithelial cells of the alveoli (Figure 3A). The level of collagen fiber deposition relatively reduced (Figure 3B), and immunohistochemical studies showed the expression of Cox-2 among the connective tissue (Figure 3C).

On the other hand, results obtained from tissue sections stained with H\&E (Figure 4A), Masson's trichrome (Figure 4B) and immunohistochemistry (Figure 4C) in the CMC group (IV) showing no significant change in the lung tissue and collagen levels. No evidence of increased fibrosis and Cox-2 positive cells in the connective tissue epithelium were observed. Furthermore, the changes were similar to those demonstrated in group two.

\section{Quantitative Morphometry}

Quantitative results related to the pulmonary alveoli and connective tissue of the mice in different groups were obtained by the morphometric method, and the percentages of contact points of alveolar spaces and pulmonary connective tissue for the four groups were determined. The mean values for the contact point of alveolar spaces in the volume unit were $39.20 \% \pm$ $8.11,52.77 \% \pm 3.39,59.17 \% \pm 7.97$, and $64.15 \% \pm$ 5.42 for the Bleo, Bleo+Thal, Thal, and CMC groups, respectively. The results indicate an increase in the alveolar spaces in the Bleo+Thal group compared to the Bleo group. Statistical analysis showed that the groups differed significantly from each other regarding the percentage of the alveolar spaces $(\mathrm{P}<0.001)$. However, in this regard, comparison of the Thal and Bleo+Thal groups $(\mathrm{P}=0.1)$ and the Thal and CMC groups $(\mathrm{P}=0.04)$ did not show statistically significant differences. The mean percentage of contact points of connective tissue in the volume unit determined for the Bleo, Bleo+Thal, Thal, and CMC groups were $59.59 \% \pm 8.87,47.22 \% \pm 3.39,40.82 \% \pm 7.97$, and $35.84 \% \pm 5.43$, respectively. This result demonstrates an increase in the amount of connective tissue in the Bleo group compared to the Bleo+Thal group. The groups differed significantly in this respect $(\mathrm{P}<0.001)$. Nevertheless, comparison of the Thal and Bleo+Thal groups $(\mathrm{P}=0.1)$ and the Thal and CMC groups $(\mathrm{P}=0.04)$ did not show significant differences. Furthermore, the mean number of Cox- $2^{+}$cells in the Bleo, Bleo+Thal, Thal, and CMC groups were 11.08 $\pm 0.6,7.54 \pm 0.6,2.36 \pm 0.32$, and $3.14 \pm 0.48$, respectively. According to the results obtained from the statistical analyses, the number of Cox-2 $2^{+}$cells in the Bleo group compared to Thal group were significantly increased $(\mathrm{P}=0.006)$. Similarly, a significant increase 

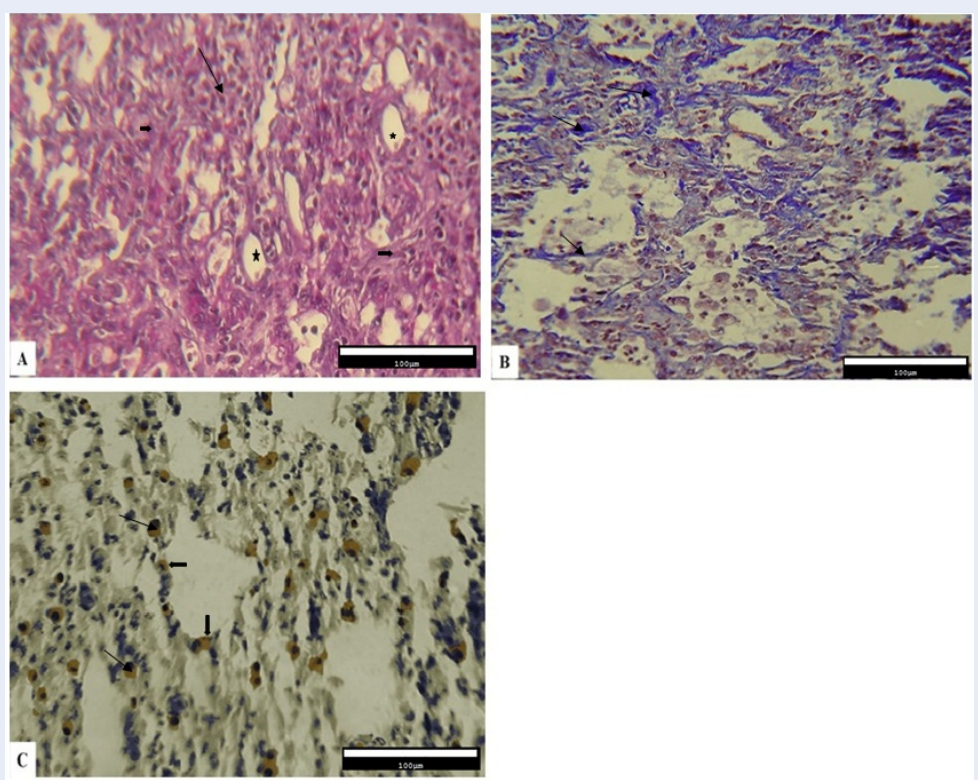

Figure 1: Histological and immunohistochemical evaluation of the lung tissue in Bleo group one. (A) (H\&E staining). The images demonstrate evidence of interstitial the lung tissue and fibroblasts cells proliferation (arrowheads), as well as the inflammatory cell infiltration (arrows). Also, the number of lung tissue alveolar spaces have a significant decrease when compared control group (open arrowheads). (B) Image of lung tissue obtained from Masson's trichrome staining. The blue color in the image indicates areas containing collage deposition that in the form of thick and coarse bands is appearance (arrows). (C) (IHC staining) shows the numerous cells with brown cytoplasm that expressing Cox-2 protein. Often of $\mathrm{Cox}_{-2}{ }^{+}$cells observed in the fibrotic region (interstitial connective tissue) through alveolar epithelial cells (arrows) and rarely were found between alveolar epithelium (arrowheads). The images were acquired at the $40 \mathrm{X}$ magnification.

in the number of $\mathrm{Cox}-2^{+}$cells was detected in the Bleo group compared to the CMC group $(\mathrm{P}=0.007)$. The number of $C o x-2^{+}$cells was significantly reduced in the Bleo+Thal group when compared to the Bleo group $(\mathrm{P}=0.012)$. However, the Thal and CMC groups were not significantly different from each other in this regard (Figure 5).

\section{DISCUSSION}

In the present study, the effect of thalidomide on the lung fibrosis, induced by intraperitoneal administration of bleomycin in mice, was investigated. The qualitative and quantitative examinations on the lung tissue of different groups were performed using histomorphometric and immunohistochemical approaches. The histological results of the Bleo group showed an impairment in alveolar walls, development of cystic modifications, increased connective tissue, and deposition of higher amounts of collagen fibers in the pulmonary connective tissue vis-à-vis the Bleo+Thal group. In this study, a significant reduction of connective tissue and a significant increase in alveolar spaces in the bleomycin thalidomide group compared to the bleomycin group suggested a decrease in fibrosis following thalidomide treatment.

As shown by the immunohistochemical studies, the number of Cox-2-expressing cells in the Bleo group increased compared to the Bleo+Thal group. According to morphometric studies, the percentage of contact points of alveolar spaces in the volume unit in the Bleo+Thal group was significantly higher than that in the Bleo group $(\mathrm{P}<0.001)$. In addition, the percentage of contact points of connective tissue in the volume unit in the Bleo group increased significantly when compared with the Bleo+Thal group $(\mathrm{P}<0.001)$. Increased connective tissue and decreased alveolar 

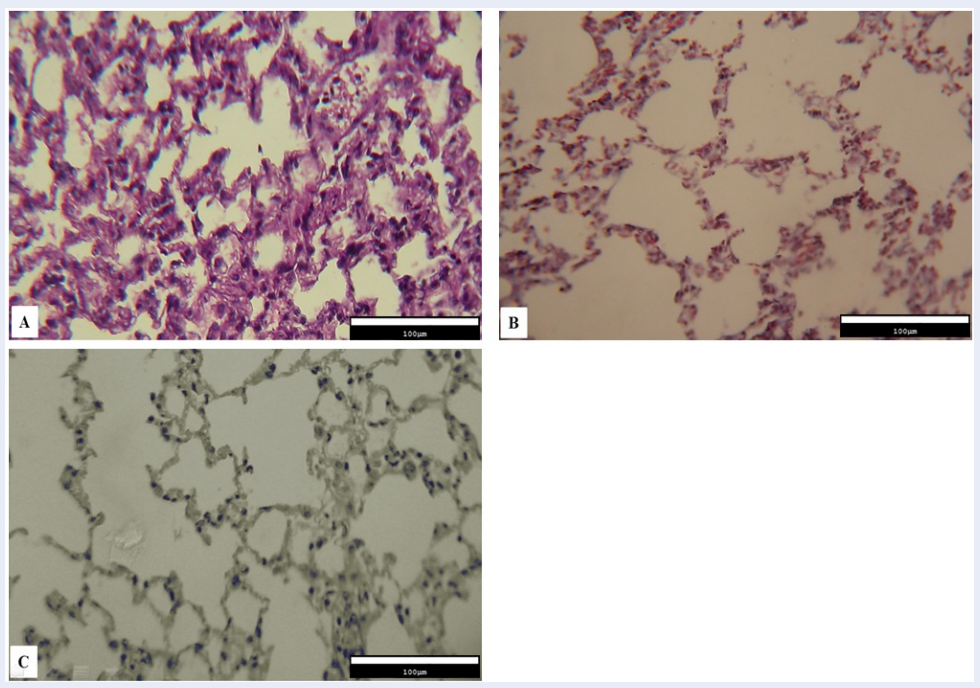

Figure 2: Histological and Immunohistochemical analysis of the lung tissue in Thal group two.(A) The lung alveolar tissues have a normal appearance, and no evidence of the congestion and inflammatory cells was observed. Also, there was no evidence of interstitial tissue remodeling. (B) The results of photomicrographs from Masson's trichrome staining. The area involved collagen fibrils, in this regard, with reduced levels of collagen. (C)Cox-2 immunohistochemistry (anti-Cox-2) shows that the number of Cox-2+ cells is rarely observed.

spaces in the Bleo group indicate pulmonary fibrosis induced by bleomycin. Moreover, according to the results of the current study, administration of thalidomide in the Belo + Thal group led to a statistically significant increase in connective tissue and an increase in the alveolar spaces compared to the Bleo group. These results indicated the alleviation of fibrosis following administration of thalidomide. Moreover, Tabeta et al. (2007) showed that thalidomide has an inhibitory effect on bleomycin-induced pulmonary fibrosis in laboratory mice ${ }^{23}$. They employed intraperitoneal administration of bleomycin for induction of fibrosis. This study showed that thalidomide had an inhibitory effect on the synthesis of collagen, TGF- $\beta$, IL-6, and VEGF; thus, it reduced the pulmonary fibrosis. In their histopathological evaluations using Azan stains, these researchers reported an increase in the thickness of the intra-alveolar wall, as well as infiltration of inflammatory cells and collagen deposition in the interstitial lung tissue in the Bleo group compared to the Bleo+Thal group ${ }^{23}$. In addition, Zhao et al. (2009) demonstrated that thalidomide has a therapeutic effect on lung fibrosis. To induce lung fibrosis in mice, they administered subcutaneous bleomycin on a daily basis. In the treatment group, oral bleomycin was administered one week before bleomycin injections. According to their results, thalidomide could be effective in the treatment of lung fibrosis via its inhibitory effect on hydroxyproline (HYP) and $\alpha$-SMA protein ${ }^{24}$. Singhal et al. (1999) demonstrated that the inhibitory effect of thalidomide on the expression of IL-6 is related to cell growth and angiogenesis; hence, the drug has been administered in multiple myeloma ${ }^{22}$. Moreover, it has been reported that thalidomide reduces the level of TGF- $\beta$, which is related to cell differentiation, and shows anti-inflammatory ${ }^{11}$, anti-angiogenesis ${ }^{12}$ , and immunomodulatory effects ${ }^{26-28}$. It seems that thalidomide can reduce induced lung fibrosis via inhibition of angiogenesis, regulation of the immune response and proliferation, and its anti-inflammatory effects. Horton et al. (2012) demonstrated that oral thalidomide in patients with lung fibrosis could significantly alleviate patients' cough ${ }^{29}$. Severe cough is one of the symptoms of lung fibrosis in patients, which is resistant to conventional therapies. It is a disabling symptom, and there are as yet no effective 


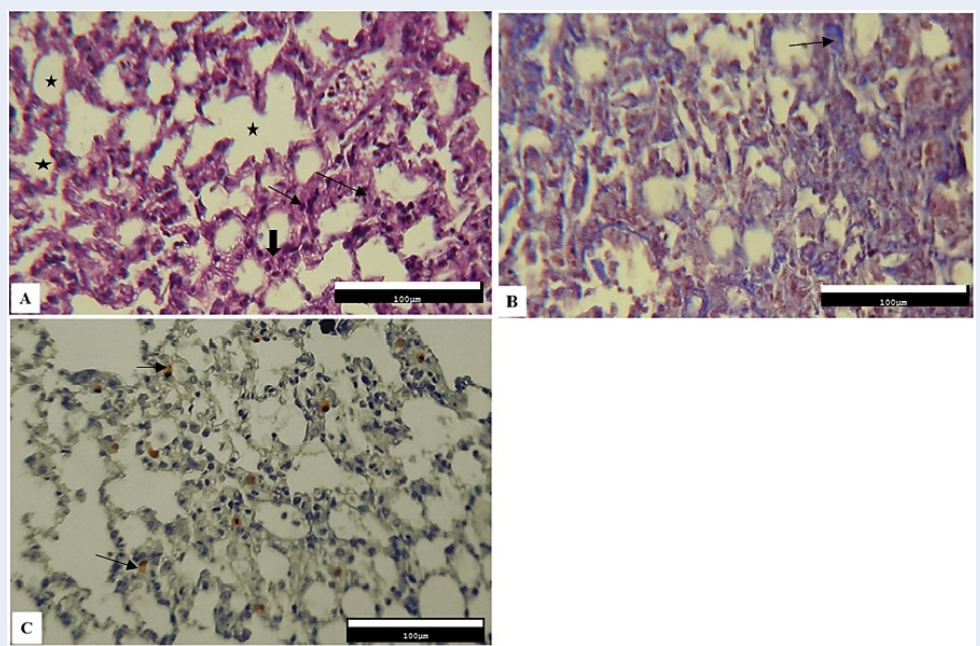

Figure 3: Histological and immunohistochemical evaluations of the lung tissue in Bleo+Thal group three.(A) H\&E staining, the image lower interstitial lung tissue thickness (arrows) and a low degree of inflammatory cell infiltration (arrowheads). Moreover, the number of alveolar and alveolar spaces were increased when compared to the control group (open arrowheads). (B) Masson's trichrome staining that blue color in the image indicates collage deposition areas (arrows). (C) IHC staining shows a decrease of distribution of $\mathrm{Cox}_{-2}{ }^{+}$cells compared to the $1^{\text {st }}$ group (arrows). A few of cells with brown cytoplasm that expressing Cox-2 protein was observed in the lung tissue (arrowheads). In addition, the $\mathrm{Cox}_{-2}{ }^{+}$cells frequently were observed in alveolar interstitial tissue (arrows). The images were acquired at the $40 \mathrm{X}$ magnification.

treatments for it. It is suggested that thalidomide can be effective in treating such patients by influencing the respiratory tract sensory nerves ${ }^{30,31}$. In the current study, the qualitative results of immunohistochemical evaluations indicated that the distribution of Cox2 protein in the Bleo+Thal group was mainly in the epithelial regions of pulmonary alveoli and respiratory bronchioles. Moreover, Cox- $2^{+}$cell count using the morphometric approaches demonstrated that the number of these cells in the Bleo+Thal group was significantly lower than that in the Bleo group $(\mathrm{P}<0.001)$. It was shown in the current study that thalidomide protects against lung fibrosis by decreasing the number of Cox-2 $2^{+}$cells. There are few reports in this aspect, and the role and expression of Cox-2 in different types of lung fibrosis is unknown. Paivaniemi et al. demonstrated in a study that an increase in the number of Cox-2-expressing epithelial cells in the lung tissue is possibly a positive prognostic factor for inhibition of fibrosis ${ }^{32}$. Prostaglandins are generated from the action of prostaglandin synthases, called cyclooxygenases. Cox-2 is the second isoform of Cox, which is inducible and is expressed following inflammation. The enzyme contributes to the development of pain, inflammation, and edema. The Cox-2 expression could be induced by inflammatory stimulants, cytokines, growth factors, and tumor promoters. This is while the enzyme is suppressed by steroidal and non-steroidal anti-inflammatory drugs ${ }^{33}$. Vancheri et al. (2004) demonstrated that in lung fibrosis, fibroblasts are unable to produce Cox-2, thereby having a defect in the production of prostaglandin E2 ${ }^{34-36}$. Additionally, Keerthisingam et al. (2001) and Xaubet et al. (2004) reported that the levels of Cox-2 and prostaglandin E2 in cultured fibroblasts derived from IPF patients ${ }^{37,38}$. However, it is shown that in cancer thalidomide inhibits lipopolysaccharide-mediated induction of inflammatory factors including Cox-2 and prostaglandin E2 in a dose-dependent manner. Moreover, the drug is shown to increase the degradation of Cox-2 mRNA, which can be helpful in the treatment of the disease ${ }^{13}$. Considering the various roles Cox-2 plays in different diseases and the complexity of the molecular mechanisms that thalidomide and Cox2 are involved in, further studies are required in this 


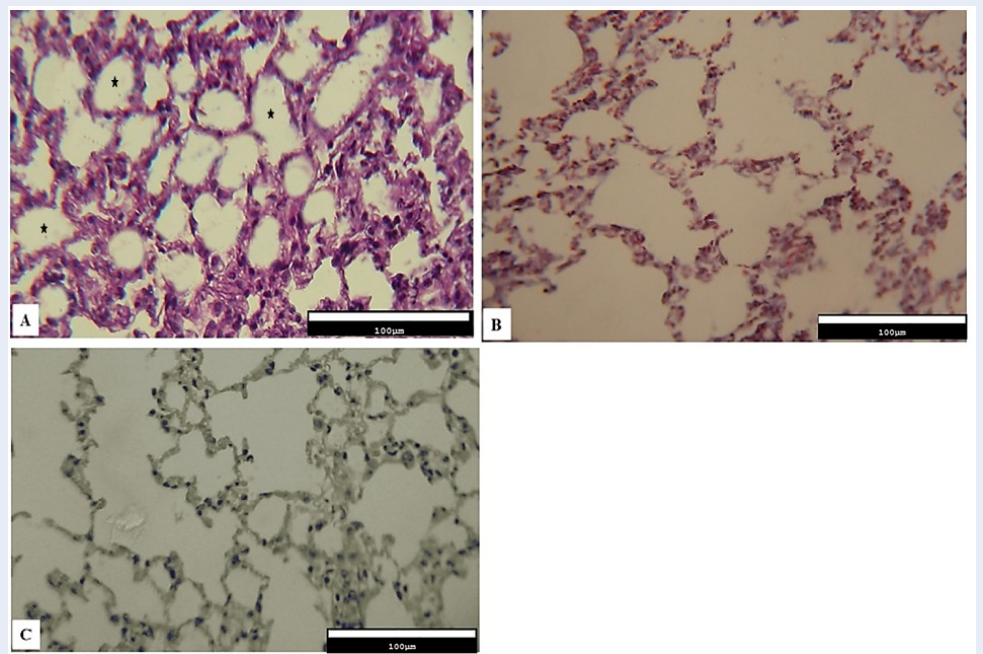

Figure 4: Histological and Immunohistochemical analyses on the lung tissue in CMC Group four.(A) The lung tissue alveolar has a normal appearance, and no evidence of the congestion and inflammatory cells was observed. Also, there is no evidence of interstitial tissue remodeling. (B) The results of photomicrographs from Masson's trichrome staining. The area involved collagen fibrils, in this regard, with reduced levels of collagen. (C)Cox-2 immunohistochemistry (anti-Cox-2) shows that the number of Cox-2+ cells is not and rarely.

field.

In this work, a significant reduction of connective tissue and a significant increase in alveolar spaces in the bleomycin thalidomide group compared to the bleomycin group could indicate a decrease in fibrosis following thalidomide use.

\section{CONCLUSIONS}

Thalidomide decreases the severity of damages in the lung, increases the number of pulmonary alveoli, and decreases the amount of connective tissue following induction of fibrosis, which is probably mediated by decreasing the expression of Cox-2 protein. As already mentioned, the thalidomide mechanism of action is complex, and there are many unknown aspects of lung fibrosis. Therefore, administration of thalidomide via other routes, as well as the induction of fibrosis in other animal models, and other times from initiation of the fibrosis process would be further investigated to compare with the results of the current study.

\section{ABBREVIATIONS}

Ardeshir Moayeri, Ayoob Rostamzadeh, Ghazal Keshavarz and Mohammad Jafar Rezaie designed the study and performed the experiments. Mansour Amraei conducted the data analysis. Mansour Amraei, and Mohammad Jafar Rezaie participated in drafting the paper; Ardeshir Moayeri and Mohammad Jafar Rezaie wrote the manuscript. All authors provided data analysis and read and approved the manuscript.

\section{COMPETING INTERESTS}

The authors report no conflicts of interest in this work.

\section{AUTHORS' CONTRIBUTIONS}

Ardeshir Moayeri, Ayoob Rostamzadeh, Ghazal Keshavarz and Mohammad Jafar Rezaie designed the study and performed the experiments. Mansour Amraei conducted the data analysis. Mansour Amraei, and Mohammad Jafar Rezaie participated in drafting the paper; Ardeshir Moayeri and Mohammad Jafar Rezaie wrote the manuscript. All authors provided data analysis and read and approved the manuscript.

\section{ACKNOWLEDGEMENTS}

We thank the Deputy Director of Research and Technology at Kurdistan University of Medical Sciences 


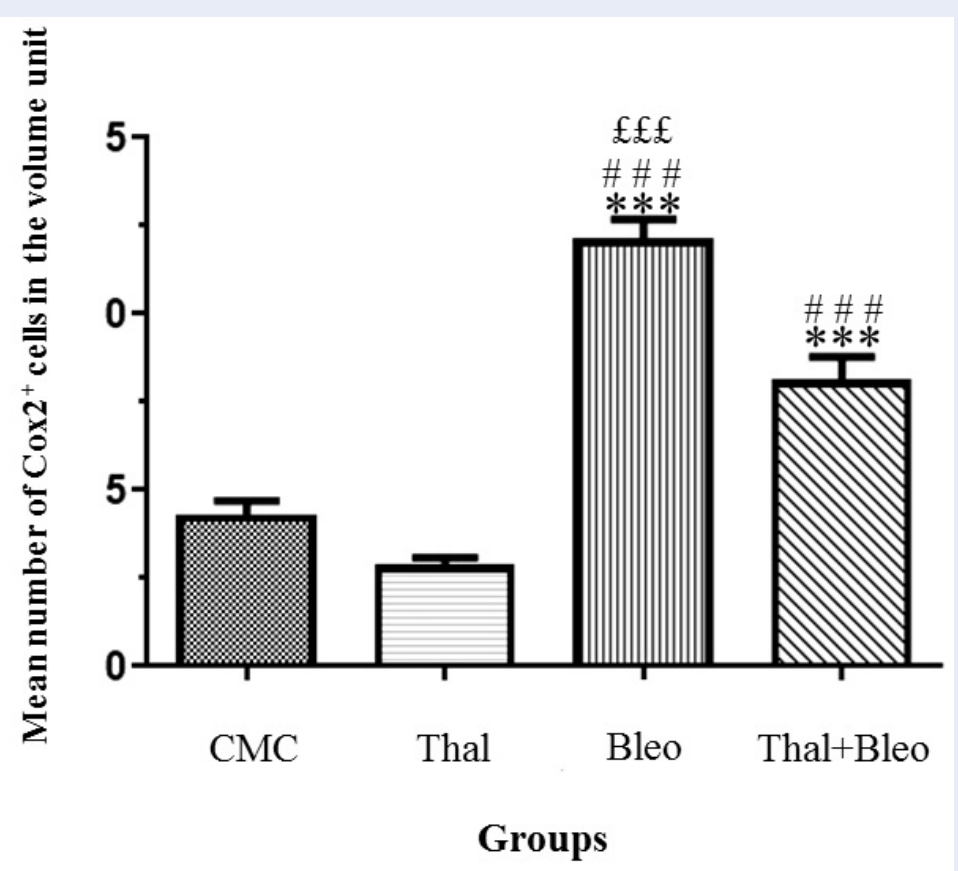

Figure 5: Results of the mean number of Cox-2 ${ }^{+}$cells in the volume unit of the lung tissue. Following immunohistochemical staining and microscopic evaluation of tissue sections, it was observed that the mean number of $\mathrm{Cox}_{-} 2^{+}$cells in the Bleo group was significantly higher than that obtained for the Thal+Bleo group $(\mathrm{P}<0.001)$. Bleo: the group that only received intraperitoneal bleomycin; Bleo+Thal: the group that received bleomycin plus thalidomide; Thal: the group that received only thalidomide; and CMC: the group that received only CMC. ${ }^{* * *}$ : $P>0.05$ vs. control group, \#\#\#: $P<0.001$ vs. Thal group, $£ £ £ P<0.001$ vs. Thal + Bleo group.

for supporting this study and the Cellular and Molecular Research Center, Kurdistan University of Medical Sciences, for their kind cooperation. Moreover, we would like to appreciate the kindness of Dr. Kaka for his assistance.

\section{REFERENCES}

1. Meyer KC. Diagnosis and management of interstitial lung disease. Transl Respir Med. 2014;2(1):4. Available from: 10.1186/ 2213-0802-2-4.

2. Kim DS, Collard HR, Jr TEK. Classification and natural history of the idiopathic interstitial pneumonias. Proc Am Thorac Soc. 2006;3(4):285-92. Available from: 10.1513/pats.200601005TK.

3. Crystal RG, Bitterman PB, Rennard SI, Hance AJ, Keogh BA. Interstitial lung diseases of unknown cause. Disorders characterized by chronic inflammation of the lower respiratory tract. N Engl J Med. 1984;310(4):235-44. Available from: 10.1056/NEJM198401263100406.

4. Richeldi L, Davies HR, Ferrara G, Franco F. Corticosteroids for idiopathic pulmonary fibrosis. Cochrane Database Syst Rev.
2003;3(3):CD002880.

5. Hagimoto N, Kuwano K, Miyazaki H, Kunitake R, Fujita M, Kawasaki $M$, et al. Induction of apoptosis and pulmonary fibrosis in mice in response to ligation of Fas antigen. Am J Respir Cell Mol Biol. 1997;17(3):272-8. Available from: 10 1165/ajrcmb.17.3.2893.

6. Piguet $P F$, Collart MA, Grau GE, Kapanci $Y$, Vassalli $P$. Tumor necrosis factor/cachectin plays a key role in bleomycin-induced pneumopathy and fibrosis. J Exp Med. 1989;170(3):655-63. Available from: 10.1084/jem.170.3.655.

7. Razavi-Azarkhiavi $K$, Ali-Omrani $M$, Solgi $R$, Bagheri $P$, HajiNoormohammadi M, Amani N, et al. Silymarin alleviates bleomycin-induced pulmonary toxicity and lipid peroxidation in mice. Pharm Biol. 2014;52(10):1267-71. Available from: 10.3109/13880209.2014.889176.

8. Gilroy DW, Colville-Nash PR, Willis D, Chivers J, Paul-Clark MJ, Willoughby DA. Inducible cyclooxygenase may have antiinflammatory properties. Nat Med. 1999;5(6):698-701. Available from: 10.1038/9550.

9. Clària J. Cyclooxygenase-2 biology. Curr Pharm Des. 2003;9(27):2177-90. Available from: 10.2174/ 1381612033454054.

10. Dubois RN, Abramson SB, Crofford L, Gupta RA, Simon LS, 
Putte LBVD, et al. Cyclooxygenase in biology and disease. FASEB J. 1998;12(12):1063-73. Available from: 10.1096/fasebj. 12.12.1063.

11. Koch HP. Thalidomide and congeners as anti-inflammatory agents. Prog Med Chem. 1985;22:165-242. Available from: 10.1016/S0079-6468(08)70231-5.

12. D'Amato RJ, Loughnan MS, Flynn E, Folkman J. Thalidomide is an inhibitor of angiogenesis. Proc Natl Acad Sci USA. 1994;91(9):4082-5. Available from: 10.1073/pnas.91.9.4082.

13. Fujita J, Mestre JR, Zeldis JB, Subbaramaiah K, Dannenberg AJ. Thalidomide and its analogues inhibit lipopolysaccharidemediated linduction of cyclooxygenase-2. Clin Cancer Res. 2001;7(11):3349-55.

14. Oliver SJ, Freeman SL, Corral LG, Ocampo CJ, Kaplan G. Thalidomide analogue CC1069 inhibits development of rat adjuvant arthritis. Clin Exp Immunol. 1999;118(2):315-21. Available from: 10.1046/j.1365-2249.1999.01039.x.

15. Schuler U, Ehninger G. Thalidomide: rationale for renewed use in immunological disorders. Drug Saf. 1995;12(6):364-9. Available from: 10.2165/00002018-199512060-00002.

16. Lee FC, Merchant SH. Alleviation of systemic manifestations of multicentric Castleman's disease by thalidomide. Am J Hematol. 2003;73(1):48-53. Available from: 10.1002/ajh.10310.

17. Bauditz J, Wedel $\mathrm{S}$, Lochs $\mathrm{H}$. Thalidomide reduces tumour necrosis factor $\alpha$ and interleukin 12 production in patients with chronic active Crohn's disease. Gut. 2002;50(2):196-200. Available from: 10.1136/gut.50.2.196.

18. Solèr RA, Howard M, Brink NS, Gibb D, Tedder RS, Nadal D. Regression of AIDS-related Kaposi's sarcoma during therapy with thalidomide. Clin Infect Dis. 1996;23(3):501-3. Available from: 10.1093/clinids/23.3.501.

19. Stebbing J, Benson C, Eisen T, Pyle L, Smalley K, Bridle H, et al. The treatment of advanced renal cell cancer with high-dose oral thalidomide. Br J Cancer. 2001;85(7):953-8. Available from: 10.1054/bjoc.2001.2025

20. Zorat F, Shetty V, Dutt D, Lisak L, Nascimben F, Allampallam $\mathrm{K}$, et al. The clinical and biological effects of thalidomide in patients with myelodysplastic syndromes. $\mathrm{Br} J$ Haematol. 2001;115(4):881-94. Available from: 10.1046/j.1365-2141. 2001.03204.x.

21. Schuppan D, Koda M, Bauer M, Hahn EG. Fibrosis of liver, pancreas and intestine: common mechanisms and clear targets? Acta Gastroenterol Belg. 2000;63(4):366-70.

22. Singhal S, Mehta J, Desikan R, Ayers D, Roberson P, Eddlemon $P$, et al. Antitumor activity of thalidomide in refractory multiple myeloma. N Engl J Med. 1999;341(21):1565-71. Available from: 10.1056/NEJM199911183412102.

23. Tabata C, Tabata R, Kadokawa Y, Hisamori S, Takahashi M, Mishima $\mathrm{M}$, et al. Thalidomide prevents bleomycin-induced pulmonary fibrosis in mice. J Immunol. 2007;179(1):708-14 Available from: 10.4049/jimmunol.179.1.708.

24. Zhao L, Xiao K, Wang H, Wang Z, Sun L, Zhang F, et al. Thalidomide has a therapeutic effect on interstitial lung fibrosis: evidence from in vitro and in vivo studies. Clin Exp Immunol. 2009;157(2):310-5. Available from: 10.1111/j.1365-2249.2009. 03962.x.

25. Bancroft JD, Gamble M. Theory and practice of histological techniques. Elsevier Health Sciences; 2008

26. Corral LG, Haslett PA, Muller GW, Chen R, Wong LM, Ocampo $\mathrm{CJ}$, et al. Differential cytokine modulation and T cell activa- tion by two distinct classes of thalidomide analogues that are potent inhibitors of TNF- $\alpha$. J Immunol. 1999;163(1):380-6.

27. Haslett PA, Corral LG, Albert M, Kaplan G. Thalidomide costimulates primary human $T$ lymphocytes, preferentially inducing proliferation, cytokine production, and cytotoxic responses in the CD8+ subset. J Exp Med. 1998;187(11):1885-92. Available from: 10.1084/jem.187.11.1885.

28. Sampaio EP, Sarno EN, Galilly R, Cohn ZA, Kaplan G. Thalidomide selectively inhibits tumor necrosis factor alpha production by stimulated human monocytes. J Exp Med. 1991:173(3):699-703. Available from: 10.1084/jem 173.3.699.

29. Horton MR, Santopietro V, Mathew L, Horton KM, Polito AJ, Liu MC, et al. Thalidomide for the treatment of cough in idiopathic pulmonary fibrosis: a randomized trial. Ann Intern Med. 2012;157(6):398-406. Available from: 10.7326/0003 4819-157-6-201209180-00003.

30. Brown KK. Chronic cough due to chronic interstitial pulmonary diseases: ACCP evidence-based clinical practice guidelines. Chest. 2006;129(1):180S-5S. Available from: 10 . 1378/chest.129.1_suppl.180S.

31. Hope-Gill BD, Hilldrup S, Davies C, Newton RP, Harrison NK. A study of the cough reflex in idiopathic pulmonary fibrosis. Am J Respir Crit Care Med. 2003;168(8):995-1002. Available from: 10.1164/rccm.200304-597OC

32. Päiväniemi $\mathrm{OE}$, Maasilta $\mathrm{PK}$, Alho $\mathrm{HS}$, Wolff $\mathrm{CH}$, Salminen US. Cyclooxygenase-2 expression in experimental post-transplant obliterative bronchiolitis. J Pathol. 2004;204(3):340-8. Available from: 10.1002/path.1631.

33. Sharma S, Sharma SC. An update on eicosanoids and inhibitors of cyclooxygenase enzyme systems. Indian J Exp Biol. 1997;35(10):1025-31.

34. Vancheri C, Sortino MA, Tomaselli V, Mastruzzo C, Condorelli $F$, Bellistrí $G$, et al. Different expression of TNF- $\alpha$ receptors and prostaglandin E(2)Production in normal and fibrotic lung fibroblasts: potential implications for the evolution of the inflammatory process. Am J Respir Cell Mol Biol. 2000;22(5):628-34. Available from: 10.1165/ajrcmb.22.5.3948.

35. McAnulty RJ, Hernández-Rodriguez NA, Mutsaers SE Coker RK, Laurent GJ. Indomethacin suppresses the antiproliferative effects of transforming growth factor- $\beta$ isoforms on fibroblast cell cultures. Biochem J. 1997;321(Pt 3):639-43. Available from: 10.1042/bj3210639.

36. Wilborn J, Crofford $\amalg$, Burdick MD, Kunkel SL, Strieter RM, Peters-Golden M. Cultured lung fibroblasts isolated from patients with idiopathic pulmonary fibrosis have a diminished capacity to synthesize prostaglandin E2 and to express cyclooxygenase-2. J Clin Invest. 1995;95(4):1861-8. Available from: 10.1172/JCI117866.

37. Keerthisingam $C B$, Jenkins RG, Harrison NK, HernandezRodriguez NA, Booth $\mathrm{H}$, Laurent GJ, et al. Cyclooxygenase-2 deficiency results in a loss of the anti-proliferative response to transforming growth factor- $\beta$ in human fibrotic lung fibroblasts and promotes bleomycin-induced pulmonary fibrosis in mice. Am J Pathol. 2001;158(4):1411-22. Available from: 10.1016/S0002-9440(10)64092-8.

38. Xaubet A, Roca-Ferrer J, Pujols L, Ramírez J, Mullol J, MarinArguedas $\mathrm{A}$, et al. Cyclooxygenase- 2 is up-regulated in lung parenchyma of chronic obstructive pulmonary disease and down-regulated in idiopathic pulmonary fibrosis. Sarcoidosis Vasc Diffuse Lung Dis. 2004;21(1):35-42. 